\title{
Globalization 2: Revisiting Neglected Tropical Diseases Such as Polio, Dengue Fever, and in Particularly EBOLA
}

\author{
Park E. Atatah'1, Catherine W. Kisavi-Atatah ${ }^{2}$ \\ ${ }^{1}$ College of Security and Criminal Justice "Social Behavioral Sciences", University of Phoenix, Phoenix, AZ, USA \\ ${ }^{2}$ Department of State Health Services, Houston, TX, USA \\ Email: peatatah12345@email.phoenix.edu, peatatah@yahoo.com, Catherine.atatah@dshs.state.tx.us, \\ ckisavi@yahoo.com
}

Received 16 November 2015; accepted 11 January 2016; published 14 January 2016

Copyright (C) 2016 by authors and Scientific Research Publishing Inc.

This work is licensed under the Creative Commons Attribution International License (CC BY). http://creativecommons.org/licenses/by/4.0/

(c) ()

\section{Abstract}

This study examined the roles globalization played in the spread of originally neglected tropical diseases like polio, dengue fever, and in particularly EBOLA from region to region between 2014 and 2015. Based on the analyzed data of the overall of spread of Ebola in 8 major critical community areas (CCA) counties in less than a year, the study found some disturbing effects. The study found that EBOLA was more rampart and showed higher identified cases as well as lower survival rates in the CCA countries. The identified Ebola cases ranged from 3429 to 1,1841 or $29 \%$ to $100 \%$ in the higher CCA countries; while at the same time, the death rates ranged from 2263 to 4301 or $53 \%$ to $100 \%$ cases. At the same time, the Ebola identified cases in the lower CCA countries ranged from 1 to 20 or $5 \%$ to $100 \%$; while the death rates ranged from 0 to 8 cases $0 \%$ to $100 \%$. As usual, the study found that neglecting tropical diseases by presumed and assumed safer regions' leaders as defensive mechanisms, were again ineffective, inefficient, and in proficient; because Ebola in particular continued to spread from region to region worldwide; regardless of efforts. The implication of this study was to assist international public health officials, public policy officials, and global leaderships to rethink, refocus, and revisit their treatments modalities, spread prevention methodologies, and practical approaches in addressing tropical neglected diseases such as polio, dengue fever, and in particularly EBOLA, which could eventually bring some positive social changes regionally; worldwide.

\section{Keywords}

Globalization, EBOLA, Vaccinations, Public Policy, Collaboration, Prevention 


\section{Introduction}

The purpose of this study was to examine the roles globalization played in the spreading of originally tropically neglected diseases from one continental area to another. This study looked into the relationships between the spread of Polio, Dengue Fever, and particularly Ebola globalization’s roles worldwide between 2014 and 2015. Statistical analyses of this study pinpointed the impacts of Ebola in 8 major countries. These countries were Liberia, Sierra Leone, Guinea, Nigeria, Senegal, Mali, Spain, and United States of America. These countries accounted for the Ebola affected critical areas between mid 2014 and March 2015 worldwide. The findings of this study should shed some lights on the roles globalization played in the spreading of originally tropically neglected diseases worldwide such as Polio, Dengue Fever, and particularly Ebola, and how to systematically control them before they became international epidemics or possibly quagmires.

\section{Ebola}

While malaria has been a topic that has been widely addressed by health officials over the years, and off cause, has become a familiar too many, this has not been the case with Ebola. While we are aware the Ebola was initially emerged in 1976 Zaire and Sudan, many in the Western countries had limited or no knowledge on this infection this is according to the Centers of Disease Control (CDC (2015 [1]). However, this is not the case to date. According to Chan as cited in The Washington Post (2014 \& 2015 [2] [3]), Ebola to date has claimed approximately 10,000 lives in Liberia, Sierra Leone, and Guinea and continues to pose a serious health challenge to many around the world. Ebola was not a serious health concern to many health care personalities in the Western Hemisphere (See WHO, 2013; Byrne, 2008; Lozano et al., 2012; McNeil, 2015 [4]-[7]). However, with the fast case identified in the United States in 2014, Ebola once an infection that was not of part of the everyday vocabulary of many health care workers in Western countries has almost become a household word.

The importation of Ebola to the United States serious impacted the way health care personalities around the world perceive the spread of diseases. It is obvious that public health care workers had and continue to have limited training and knowledge of this infection and obviously ill prepared to handle this infection leaving them vulnerable to the spread of this infection. United States is a well-traveled country and chances of importing disease are highly likely. Therefore, health care workers cannot remain ignorant to the fact that disease that impact one region can easily penetrate another region. As such, working together from a global perspective in addressing disease prevention and control is vital for health care personalities all over the world. Ebola is clearly a good example that clearly shows that we are not take disease outbreak in one region for granted. Besides Ebola, polio is yet another previously controlled tropically disease resurfacing in some Africa, Asia, and Eastern countries recently.

\section{Polio}

Polio, a virus spread through feces often lives individuals with devastating health problems including death. Unfortunately with no known cure, health care personalities have to remain proactive in ensuring that at risk populations are vaccinated. Failing to do so can not only impact high risk countries but the importation of this virus unavoidable due to importation. In 2010, Polio Global Eradication Initiative warned that countries that have managed to eradicate wild polo virus importation could be at risk of Polio importation due to globalization. Polio Global Eradication Initiative reported that Polio importation can occur in any country. As such, applying intervention strategies to help elevate outbreaks is strongly recommended.

Additionally, Bennett and Palau (2013 [8]) reported that even though Nigeria, Afghanistan, and Pakistan were previously considered the highest endemic countries, in 2013 it was reported that in other countries this virus in re-emergence elsewhere internationally. Above all, over the years Centers for Disease Control and Prevention, United Children’s Fund, WHO, Rotary International, U.S. as well as Bill \& Melinda Gates Foundation have partnered in the efforts to eradicate this virus. On a serious note, the reemergence of polio worldwide is now becoming an old but eradicated phenomenon that is systematically becoming an old but a new epidemic to deal with internationally.

\section{Dengue Fever}

Historically speaking, "the first record of a case of probable dengue fever is in a Chinese medical encyclopedia 
from the Jin Dynasty (265 - 420 AD) which referred to a "water poison” associated with flying insects" (Anonymous, 2006 \& Gubler, 1988, para. 1 [9] [10]). It is believed that Dengue fever's primary vector “A. aegypti, spread out of Africa in the 15th to 19th centuries due in part to increased globalization secondary to the slave trade (9, para. 1). While dengue fever originated from China, its journeys to Africa remain a mystery. However, record has it that describing dengue fever as epidemics started in the $17^{\text {th }}$ century; however, its overwhelming noticeable spread as epidemics occurred between 1779 and 1780, when an epidemic swept across Asia, Africa, and North America [9] \& [10]. But, since 1940, dengue fevers as epidemics were infrequent [10]. Interestingly, it appeals that dengue fever is revisiting North America especially in Texas, Louisiana, South and North Carolina and other southern coastal states as early as 2008. It should be noted that records have it that majority of dengue fever occurrences in North America are not considered as epidemic. But, this is not the case with South and Central America according to the pinpointed dengue geographical distribution in 2006 (See Brady OJ, et al., 2013; Who, 2012; Neglected Topical Diseases WHO, 2013; WHO, 2009; Torrey \& Yolken, 2005 [11]-[15]).

\section{Methodology}

This study investigated Ebola globalization roles using Non-Experimental Descriptive design measurements concentrating on Ebola active secondary data obtained from WHO (2015 [16]) records. These measurements concentrated on general descriptive statistics, percentile values, central tendencies, dispersions, and distribution of data, along with one-way sample statistics test, and a confidence interval differences test. Nominal scale was used as the scale of measurement in this study. Non-Experimental Descriptive study relies on the statistical analyses of existing secondary data, through comprehensive measurements of the above mentioned measurements' perimeters (see Creswell, 2009 [17]; Miller, 1981 [18]; Morrow, 2011 [19]; Frankfort-Nachmias \& Nachmias, 2000; 2008 [20] [21]). This data analyses examined the overall of Ebola cases in these 8 major countries; and the Ebola deaths cases recorded in these countries according to WHO.

\subsection{Data Collection}

These database analyses examined the overall of spread of Ebola in 8 major critical community areas (CCA) counties such as Liberia, Sierra Leone, Guinea, Nigeria, Senegal, Mali, Spain, and United States of America as a result of globalization effects. This research study implemented a specific purposeful "multiple case study" by collecting samples from 8countries using the application of "cluster data sampling" sample collection technique. The data were collected through a comprehensive collaboration of WHO and CDC Ebola Situation Report on March 25, 2015 from 2014 to March 2015 (see WHO, 2015; 2015; 2014; 2015; 2014; 2014; 2015; 2014; CDC, 2014; 2015 [22]-[31]). In fact, since all needed secondary data were available, Atatah et al. (2013 [32]), Statistical Significant Differences Multiplier (SSDM) was not needed for future data projections or estimations in this study.

\section{Research Questions}

This quantitative research study investigated two major research questions. These questions were:

1. Research Question 1. RQ 1: What are the relationships between globalization "Global Village" and the spread of contagious tropical neglected diseases such as Ebola from one country to another worldwide?

2. Research Question 2. RQ 2: What are the motivating factors in the spreading of tropical neglected diseases such as Ebola from one country to another worldwide?

\subsection{Data Analyses of the Study}

Since Polio, Dengue Fever, and Ebony appeared to be the most popular new comers to United States of America in 2014 and possibly 2015, comprehensive statistical analyses of the roles globalization play with the spreading of tropically neglected diseases were analyzed. This study singularly concentrated on the Ebola outbreaks in Africa and beyond between early 2014 and early 2015 specifically dealing with identified Ebola cases and Ebola deaths in these 8 major critical countries.

Table 1 indicated active secondary statistical data obtained from June 2014 until March 2015 of Ebola cases in pinpointed active areas. These areas Guinea, Liberia, Sierra Leone, Mali, Nigeria, Senegal, Spain, United Kingdom, and United States of America. Of the analyzed data, Guinea, Liberia, and Sierra Leone were considered to be statistical significant differences active Ebola cases areas. On the other hand, the other areas were 
Table 1. Descriptive statistics of Ebola cases and deaths.

\begin{tabular}{cccccc}
\hline & & \multicolumn{3}{c}{ Descriptive Statistics } \\
\cline { 2 - 5 } & $\mathrm{N}$ & Minimum & Maximum & Mean & Std. Deviation \\
\hline Ebola Cases & 8 & 1.00 & 11841.00 & 3113.2500 & 4878.92851 \\
Ebola deaths & 8 & 0.00 & 4301.00 & 1290.7500 & 1864.38789 \\
Valid N (listwise) & 8 & & & & \\
\hline
\end{tabular}

more or less statistically insignificant differences areas as one of the analyzed data was eliminated due to 8 valid items shown above. These areas accounted for the Ebola active places between mid 2014 to March 2015. The maximum (Max) Ebola cases were 11841; while Ebola maximum (Max) deaths were 4301 with Standard Deviation (SD) of 4879 and 1864 respectively. The minimum (Min) Ebola cases and Ebola deaths were 1.00 and .00 respectively (see Table 1 as shown above).

Table 2 indicated the high cases of Ebola to be 11841 while the high deaths cases was 4301. The range of cases and deaths remained the as the maximum (Max) cases. The Mean of Ebola cases were 3113 while the Ebola deaths Mean were 1291 while the Minimum (Min) cases/deaths were 1.00 and .00 respectively. The Medium (Med) were 14.0 and 7.0 respectively while the Standard Error of Mean (SEM) was 1725 and 659 respectively while the Standard Deviations (SD) were 4879 and 1864. The Variances (V) of cases/deaths were 23,803,943 and 3,475,942 respective (see Table 2 as shown above).

Table 3 indicated the Ebola Cases cumulative frequency with the Cumulative Percent (CP) of 25.0, 37.5, 62.5 and 100.0 which showed no missing data as shown above.

Table 4 indicated the Ebola Deaths cumulative frequency with the Cumulative Percent (CP) of 25.0, 37.5, 62.5 and 100.0 which showed no missing data (see Table 4 as shown above).

There were no changes in valid percentages of Ebola Cases and Ebola Deaths data as shown above. Of the obtained data, $100 \%$ of the data were included in these analyses.

Figure 1 represented the Ebola cases frequency from mid 2014 to March 2015 in 8 valid countries with centralized active cases in left hand area and others were inactive. The Std. Dev was 4879, the Mean was 3113 and $\mathrm{N}$ is 8 (see Figure 1 as shown above).

Figure 2 represented the Ebola deaths frequency from mid 2014 to March 2015 in 8 valid countries with centralized active cases in left hand area and others were inactive. The Std. Dev was 1864, the Mean was 1291 and $\mathrm{N}$ is 8 (see Figure 1 as shown above).

Figure 3 represented Ebola cases from 2014 to 2015 with the lower point of 1.00, midpoint of 20 cases in the inactive areas; while the midpoint was 3429 while the high cases were 11841 (see Figure 3 as shown above).

Figure 4 represented Ebola deaths frequency from 2014 to 2015 with the lower of 0.00, midpoint of 8.00 cases in the inactive areas; while the midpoint was 2263 while the high cases were 4301 (see Figure 4 as shown above).

Table 5 showed a one-sample statistics of Ebola cases and Ebola Deaths from mid 2014 to March 2015. The $\mathbf{N}$ was 8, the ME were 3113 and 1291 while the SEM were 1725 and 659 (see Table 5 as shown above).

Table 6 showed a One-Sample Test of Ebola Cases and Ebola Deaths (t) were 1.81 and 1.96, (df) were 7 and 7 and the Sig (2-tailed) were 0.114 and $0.091>0.5$ (CI) respectively. Therefore, data showed no statistical significant differences since measurements simply concentrated on Ebola Cases and Ebola Deaths in pinpointed critical regions from mid 2014 until March 2015 (see Table 6 as shown above).

\section{Results of the Study}

\section{Ebola}

In Guinea for example, of the 3429 identified Ebola cases, 2263 or approximately $66 \%$ of them passed away. Similarly in Liberia, of the 9602 identified Ebola cases, 4301 or approximately $45 \%$ of them passed away. Additionally, in Sierra Leone of the 11841 identified cases, 3747 or approximately 32\% passed away. In short, Ebola is a nightmare because of its short duration of elimination. However, in the lower one to one correspondence 
Table 2. Statistical analysis of Ebola cases and Ebola deaths.

\begin{tabular}{|c|c|c|}
\hline & \multicolumn{2}{|c|}{ Statistics } \\
\hline & Ebola Cases & Ebola Deaths \\
\hline \multirow{3}{*}{$\begin{array}{c}\text { Valid } \\
\text { Missing }\end{array}$} & 8 & 8 \\
\hline & 0 & 0 \\
\hline & 3113.2500 & 1290.7500 \\
\hline Std. Error of Mean & 1724.96172 & 659.16066 \\
\hline Median & 14.0000 & 7.0000 \\
\hline Mode & 1.00 & 0.00 \\
\hline Std. Deviation & 4878.92851 & 1864.38789 \\
\hline Variance & 23803943.357 & 3475942.214 \\
\hline Skewness & 1.293 & 0.950 \\
\hline Std. Error of Skewness & 0.752 & 0.752 \\
\hline Kurtosis & -0.035 & -1.121 \\
\hline Std. Error of Kurtosis & 1.481 & 1.481 \\
\hline Range & 11840.00 & 4301.00 \\
\hline Minimum & 1.00 & 0.00 \\
\hline Maximum & 11841.00 & 4301.00 \\
\hline Sum & 24906.00 & 10326.00 \\
\hline
\end{tabular}

Table 3. Ebola cases cumulative frequency.

\begin{tabular}{cccccc}
\hline & & \multicolumn{3}{c}{ Ebola Cases } \\
\cline { 3 - 6 } & & Frequency & Percent & Valid Percent & Cumulative Percent \\
\hline \multirow{3}{*}{ Valid } & 1.00 & 2 & 25.0 & 25.0 & 25.0 \\
& 4.00 & 1 & 12.5 & 12.5 & 37.5 \\
& 8.00 & 1 & 12.5 & 12.5 & 50.0 \\
& 20.00 & 1 & 12.5 & 12.5 & 62.5 \\
& 3429.00 & 1 & 12.5 & 12.5 & 75.0 \\
& 9602.00 & 1 & 12.5 & 12.5 & 100.0 \\
\hline
\end{tabular}

Table 4. Ebola deaths cumulative frequency.

\begin{tabular}{|c|c|c|c|c|c|}
\hline & & \multicolumn{4}{|c|}{ Ebola deaths } \\
\hline & & Frequency & Percent & Valid Percent & Cumulative Percent \\
\hline \multirow{8}{*}{ Valid } & 0.00 & 2 & 25.0 & 25.0 & 25.0 \\
\hline & 1.00 & 1 & 12.5 & 12.5 & 37.5 \\
\hline & 6.00 & 1 & 12.5 & 12.5 & 50.0 \\
\hline & 8.00 & 1 & 12.5 & 12.5 & 62.5 \\
\hline & 2263.00 & 1 & 12.5 & 12.5 & 75.0 \\
\hline & 3747.00 & 1 & 12.5 & 12.5 & 87.5 \\
\hline & 4301.00 & 1 & 12.5 & 12.5 & 100.0 \\
\hline & Total & 8 & 100.0 & 100.0 & \\
\hline
\end{tabular}




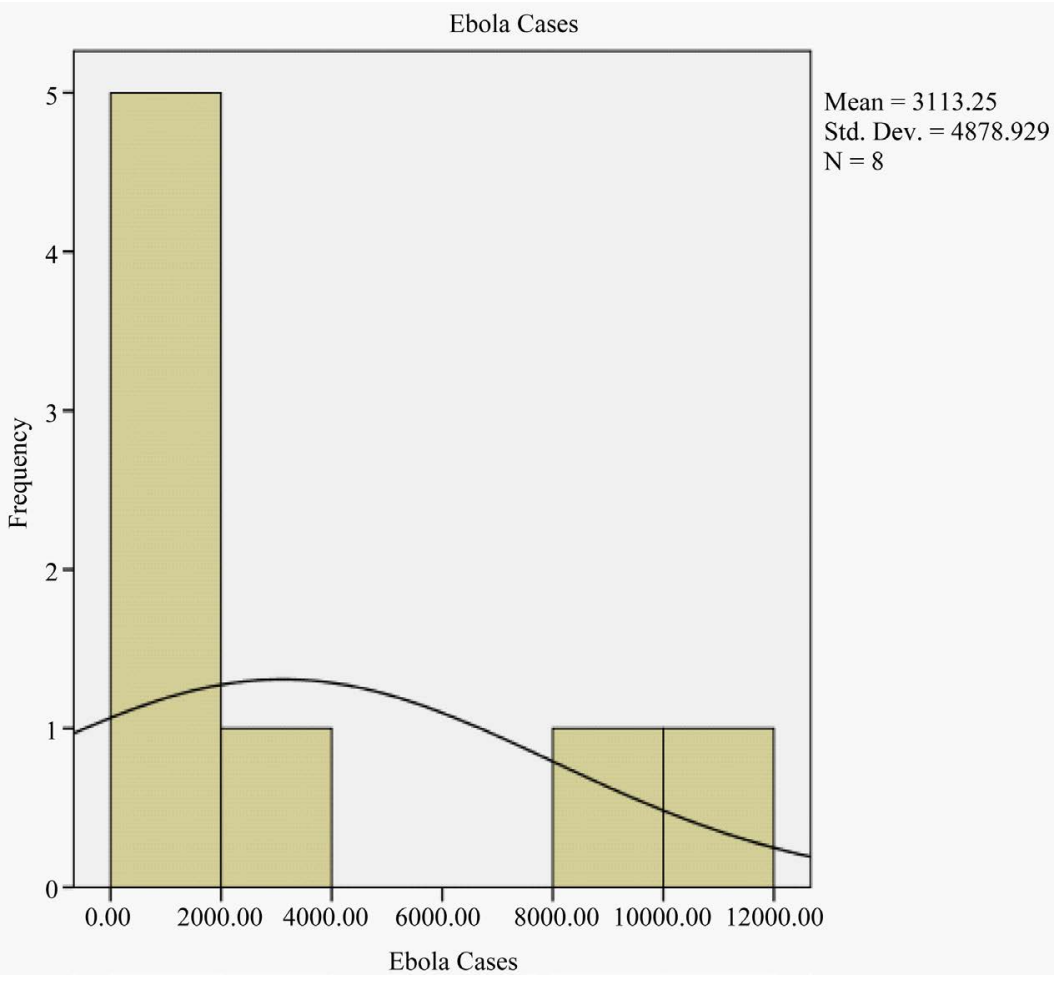

Figure 1. Ebola cases frequency.

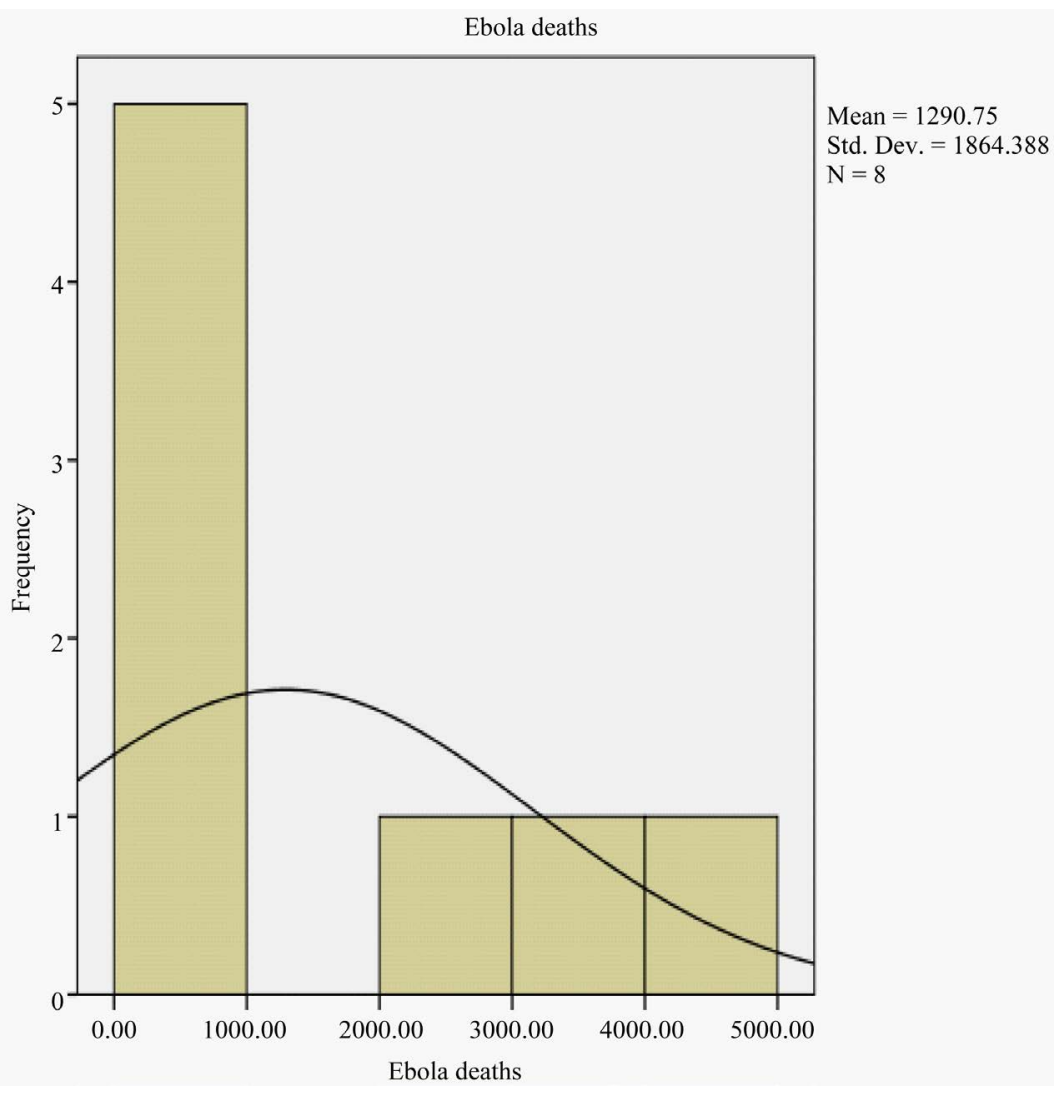

Figure 2. Ebola deaths frequency. 


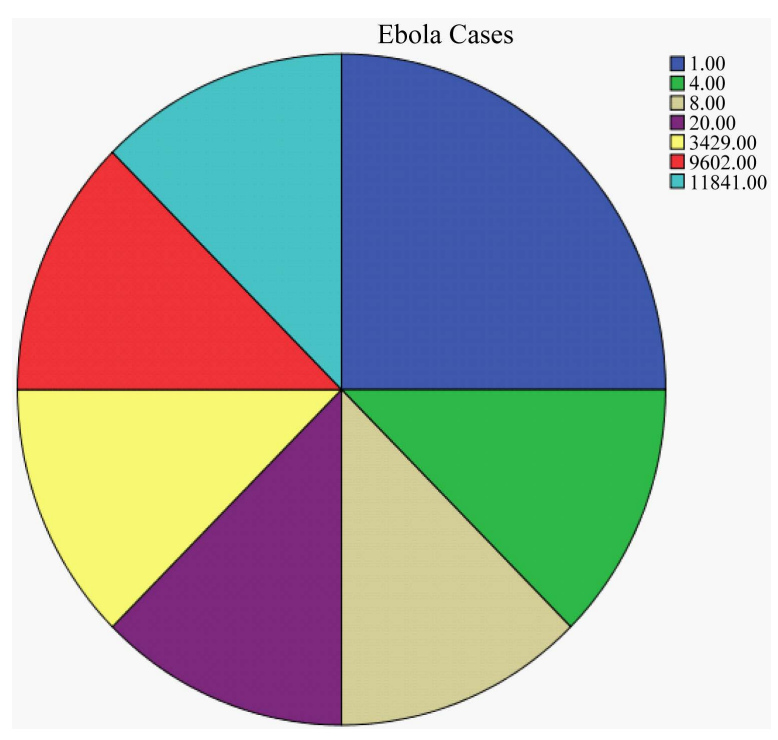

Figure 3. Ebola cases frequency representation pie chart.

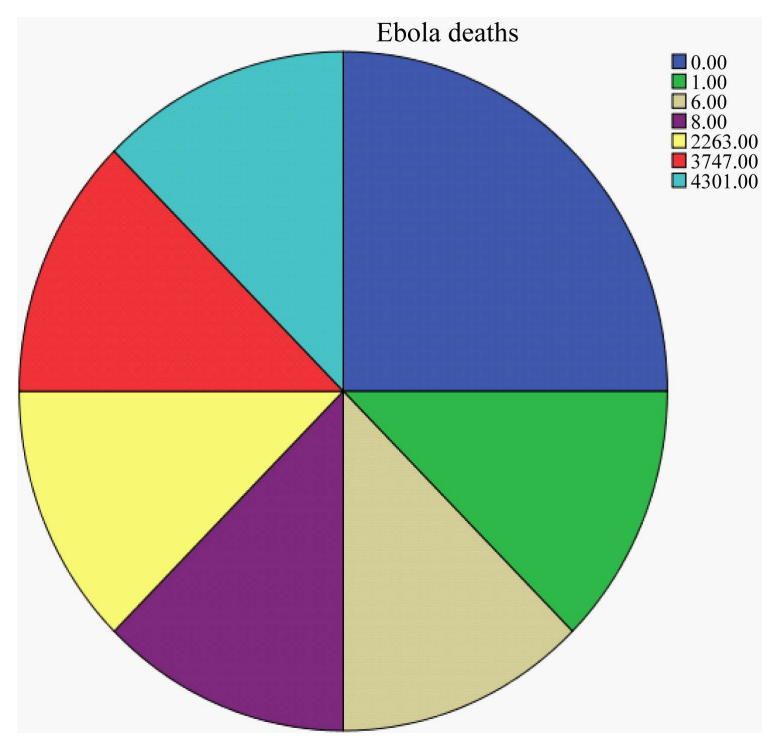

Figure 4. Ebola deaths frequency representation pie chart.

Table 5. One-sample statistics of Ebola cases and Ebola deaths.

\begin{tabular}{ccccc}
\hline & & \multicolumn{3}{c}{ One-Sample Statistics } \\
\cline { 2 - 5 } & $\mathrm{N}$ & Mean & Std. Deviation & Std. Error Mean \\
\hline Ebola Cases & 8 & 3113.2500 & 4878.92851 & 1724.96172 \\
Ebola deaths & 8 & 1290.7500 & 1864.38789 & 659.16066 \\
\hline
\end{tabular}

critical areas, we found that the death cases' numbers were relatively lower than those in the higher critical areas such as Guinea, Liberia, and Sierra Leone. For instance, in Mali, 6 out of the 8 identified Ebola cases or 75\% passed away. This shows that critical areas lack the marginal propensity to effectively, efficiently, and proficiently tackle highly contagious such as Ebola due to unknown internal and external factors.

While this was a higher percentage in the lower critical areas, however, from a one-to-one correspondences' viewpoint, this was a lower number as compared to the numbers in higher critical areas. In Nigeria, 8 out 20 
Table 6. One-sample test of Ebola cases and Ebola deaths.

\begin{tabular}{|c|c|c|c|c|c|c|}
\hline \multicolumn{7}{|c|}{ One-Sample Test } \\
\hline & \multicolumn{6}{|c|}{ Test Value $=0$} \\
\hline & \multirow{2}{*}{$\mathrm{t}$} & \multirow{2}{*}{ df } & \multirow{2}{*}{ Sig. (2-Tailed) } & \multirow{2}{*}{ Mean Difference } & \multicolumn{2}{|c|}{ 95\% Confidence Interval of the Difference } \\
\hline & & & & & Lower & Upper \\
\hline Ebola Cases & 1.805 & 7 & 0.114 & 3113.25000 & -965.6363 & 7192.1363 \\
\hline Ebola deaths & 1.958 & 7 & 0.091 & 1290.75000 & -267.9173 & 2849.4173 \\
\hline
\end{tabular}

identified Ebola cases or 40\% passed away. But surprisingly, in Senegal 1 identified case of Ebola or 100\% survival case and so were the identified Ebola cases in Spain and United Kingdom to be specified. However, in the United States of America 1 identified Ebola case out 4 cases or $25 \%$ passed away. Collectively statistically speaking, of the 24,907 total identified Ebola cases in the 8 critical areas, 10326 cases or approximately $42 \%$ actually passed away; and, this makes Ebola one of the most contagious originally tropical neglected diseases, based on its destructive pathways, and its overall destructive metamorphosis.

Based on the above findings, it is arguable that while it has been repeatedly said that "There is no cure for Ebola," the question now becomes how did those identified Ebola cases in the lower critical areas not only survive; but, how did they overcame Ebola? This is a lingering question that needs to be answered by public health officials as well as international leaderships. For example, in the United States, one victim was identified and actually passed away due to lack of positive identification and lack of treatment. Additionally, majority if not all identified cases outside Africa actually imported Ebola while they were them as treatment practitioners. Also, for the first time since World War II, quarantine became an acceptable phenomenon as compared to the pass [33]-[37]. For the first time, Western world now know that Ebola is not simply an African epidemic; instead, it is a quagmire the world should and must address for possibly years to come. Based on the above pinpointed statistical analyses, yes indeed, Ebola is not only a household name; but instead, Ebola is a classical phenomenon of the "old but newer normal approach of contagious diseases".

Additionally, as Atatah and Kisavi-Atatah (2015 [38]) previously argued, we also further found that originally neglected tropical diseases such as polio, dengue fever, and particularly Ebola, are resurfacing from one geographical location to another due to the concept of globalization or "Global Village" phenomenon. A phenomenon that makes it possible for one infested person to travel to another region knowingly or unknowing, and eventually infest whomever he or she has comes in contact with, particularly when dealing with contagious disease such as Ebola. For example, majority if not all the imported or exported identified Ebola beside those in the critical Ebola areas were either imported or exported. This shows a clear one-to-one correspondence when dealing with the role globalization "Global Village" mentality plays in the importations or exportations of contagious diseases, particularly Ebola. We also found that the three major contributing factors in spreading of originally tropically neglected diseases such as polio, dengue fever and in particularly Ebola were transportation (importations or exportations) immigration of people, easy transportation accessibility, and internal conflict regions.

\section{Statistical Analysis of the Study's Findings}

As previously assumed, in this study, we found that there was a direct relationship between globalization "Global Village" and the spread of tropically neglected diseases such as others and particularly Ebola from regions to regions. We hypothesized with two major hypotheses which were:

Alternative Hypothesis $\boldsymbol{H}_{1} \mathbf{1}$ : There was a direct relationship between globalization "Global Village" and the spread of tropically neglected diseases such as polio, dengue fever, and particularly and especially Ebola worldwide.

Null Hypothesis $\boldsymbol{H}_{\mathbf{0}} \mathbf{1}$ : There was no relationship between globalization "Global Village" and the spread of tropically neglected diseases such as polio, dengue fever, and particularly and especially Ebola worldwide.

As such, we rejected the Null Hypothesis; instead, we accepted the accepted the Alternative Hypothesis that:

Based on these findings, we rejected the Null Hypothesis and accepted the Alternative Hypothesis. Also, kurtosis showed -0.035 in indentified Ebola cases; but -1.121 in Ebola death cases between summer 2014 and 
March 2015 Also, skewnesses were 1.293 in Ebola identified cases and 0.950 in Ebola death cases between summer 2014 and March 2015. However, there was a balance statistical data distribution in this study because the Std. Error of Skewnees (Std.ES) were 0.752 in Ebola identified cases versus 0.752 in Ebola death cases between Summer 2014 and March 2015. While, the Ebola identified cases and death cases' Std. Error of Kurtosis (Std. EK) were 1.481 and 1.481 respectively in all cases between summer 2014 and March 2015. This indicated a statistical balanced data distribution in this study; as such, we rejected the Null Hypothesis and accepted the Alternative Hypothesis (see Table 2 as shown above).

Above all, there were statistical significant differences between globalization "Global Village" mentality and the spread of tropical diseases such as contagious and in particularly Ebola from one region to another. This is the case because in a One-Sample Test of Ebola Cases and Ebola Deaths (t) were 1.81 and 1.96, (df) were 7 and 7 and the Sig (2-tailed) were 0.114 and $0.091>0.5$ or $95 \%$ (CI) or > than 0.025 or $97.5 \%$ (CI) in each tailed respectively. The records showed that approximately $89 \%$ to $90 \%$ of all Ebola identified and Ebola death cases were somehow imported or exported (in the critical areas) from one region to another worldwide (see Table 1, Table 2 \& Table 6). As a matter of fact, Sierra Leone, Guinea, and Liberia fell into the classical definition of the critical community size (CCS) which populations are plagued by evolutionary implications (Black, 1966; UN, 2013; Offit, 2007; BBC News, 2006 [39]-[42]). Basically, globalization plays some vital roles in the importations and exportations of Ebola from critical regions to other regions worldwide. We summed that there is a direct relationship between globalization and the importation or exportation of Ebola from one region to another.

\section{Implications of the Study}

Similarly to previous study which also looked into globalization's roles in the spread of contagious diseases such as measles, this quantitative research study shed three major lights as implications for the world to address today and tomorrow to come. First, this research study showed that the days of allowing certain diseases such as tropical diseases like polio, dengue fever, and particularly Ebola to be fully neglected, are over (see Atatah \& Kisavi-Atatah, 2015 [38]). This is the case because old but newer phenomenon such as globalizations "Global Village" actually accelerates the spreading of such diseases from regions to regions like wild fires. Secondly, the world should realize that as previously echoed by historic intellectual psychologists and prophets in the past, "We are all tied together as one inescapable network; that whatever touches one directly, touches the rest us indirectly eventually” (Dr. Martin Luther King, Jr. 1963-1968, personal communication) (see Atatah \& KisaviAtatah, 2015 [38]) because Ebola is closer to you; than you imagined.

In short, the third implication of this study is for the first time the world has seen and symmetrically accepted issues associated with quarantine and isolations of Ebola patients (CDC, 2014; 2015 [33]-[35] [43] [44]). Besides the above, the world also saw and accepted how to dealing with seas airports' passengers, travelers quarantine methodologies, associative legal issues, among many to mention a few inconveniences associated with Ebola (see CDC, 2014; 2015 [33]-[35] [43] [44]). These are some of the most pressing implications, the world should and must collaboratively, collectively, and holistically address, before they become international endless quagmires for all. Furthermore, this study should bring some positive social changes to the rest of the world eventually; if, some of the recommendations are holistically reviewed, initiated, developed, and implemented effectively, efficiently, and proficiently.

\section{Discussion and Conclusion}

In summation as previously emphasized, this comprehensive research study made it possible to look into a historic phenomenon of globalization "Global Village" inputs in the spread of tropical neglected diseases from one region to another. This study shows that factors such as exportations and importations of goods and human encourage the spread of tropical neglected diseases particularly Ebola from one region to another expeditiously. Also, according to a pinpointed personal communication in a public radio by Baylor University Center for Tropically Neglected Diseases department in 2015, one of the largest factors responsible for the spread of tropical diseases from region to region was humanistic crisis. For example, Ebola (a contagious disease) was still more prevalent in Guinea, Sierra Leone, and Liberia in Africa which had been repeatedly decimated by internal civil wars (humanistic crisis) for generations. He summed that there was a direct relationship between uncontrollable domesticated civil wars and the mobilizations of neglected tropical diseases such as Ebola and among others, from one crisis area to another (see Atatah \& Kisavi-Atatah, 2015 [38]). 
In should be noted that last year (2014), Baylor University became the first higher learning institution in America to open a full flagged school/department to deal singularly with majority of tropical neglected diseases' old and new phenomena (see CDC, 2014; CDC 2015, [33]-[37] [43] [44]; \& WHO, 2014; WHO, 2015 [22][29]). But, Baylor University should understand that singular approach never won. On average, western experts had limited understanding of the metamorphisms of tropically neglected diseases evolution. As such, collective collaboration of further experts' inclusiveness, rather than experts' exclusiveness was always superior to all. This fell under the philosophical belief of “Divided we fall; and united we stand” (Dr. M. L. King, Jr. 1963-1968, personal communication). This was the case because neglected diseases such as Ebola and among others were resurfacing symmetrically worldwide; yet, we had no definite control over their revalidations. This analysis fell under the social constructionism of the reality of ideological theory; which was developed by Berger and Luckmann in 1966 [45]. In fact obviously, skewed ideologies led to skewed public policies initiations, developments, and implementations; which usually led to fundamental holistic counterproductive outcomes across the board, in the final analysis (see Atatah \& Kisavi-Atatah, 2015 [38]).

Another interesting finding of this comprehensive study was to showcase the issues associated with neglected diseases implications and how to address them before they became unsustainable quagmires. Therefore, the findings of this study served as a drawing board for public health officials to constructively rethink and revisit the dynamics associated with tropically neglected diseases and found out ways to address them comprehensively. For example, tropical neglected diseases lacked the ability, capability, and capacity to move from one region to another without any humanistic assistance. Precisely, this was where globalization "global village” ideology played a pivotal role in the form of transportation, exportation, and importation, among others, just to mention a few. In other words, there was a significant marginal propensity relationship between "globalization” and the spread of tropical neglected diseases such as malaria and particularly Ebola from one coast to another coast; worldwide.

In conclusion, the world should know that majority of neglected tropical diseases are currently mushrooming into a new and modern phenomenon that needs to be comprehensive and collaboratively addressed internationally. Failure to address these neglected tropical diseases such as malaria and particularly measles will give them the opportunity to develop stronger concentrated strings that could pose unsustainable challenges for the world to deal with periodically; and possibly repeatedly. In the final analysis, one thing is clear. Globalization appears to be the genesis of importation and exportation of neglected tropical diseases worldwide. For example, Ebola outbreak in 2014 and 2015 is a classical example of the old but new phenomena that was previously ignored by the world; yet, it resurfaced internationally changing the ways public health care personalities have to deal with tropically neglected diseases outlooks.

Finally, public health care personalities around the world should collaborate and understand that globalization is now a new phenomenon that has changed the ways public health crisis are addressed. These are lessons learned and insights gained the world should and must remember when dealing with the spreading of any contagious diseases in general; but, particularly Ebola worldwide. In fact, there is no doubt that it is an understatement to state that "Ebola is a Quagmire" with no immediate solutions. However, as public health practitioners, we must and should be hopeful that if recommendations are collaboratively, collectively, and carefully implemented, we should see some positive social change in the near or far future when dealing with EBOLA. This is the case because when it comes to Ebola, the world sees it as the "improbabilities of the possibilities and the possibilities of improbabilities” in 2014 and 2015 due to historic overall neglect worldwide. Ebola has becomes the unknown paradigm. However, as argued by Atatah and Kisavi-Atatah (2015 [38]) about the "Paradigm of Life", "The paradigm of life is the internalization of the factorized intrinsic of the presences; while the past is the externalization of the factorized extrinsic of the occurrences. However, the fundamental measurements or the factorizations of the actual futures are always ruled by mildness, moderateness, or severances of the unknowns, undefined, and unmarked rulers; who are always accompanied with or by humanistic skepticisms” (para. 1 [45]). And, that is the "Paradigm of Life" when dealing with EBOLA in 2014 and 2015; yet, its future still remains a humanistic skepticisms’ quagmire.

\section{Recommendations}

The recommendations of this study are as followed:

The general recommendations in our initial visitation remain the same for the tropical and other regions; however, additional recommendations are added for the pharmaceutical companies. 


\section{Tropical Regions}

1. First, it should be noted that tropical neglected diseases such as malaria and measles are common in the tropical regions; and, tropical regions public health officials and public policymakers should develop better systematic ways in addressing them repeatedly; instead of waiting until they become epidemics.

2. Tropical regions leaderships should be self-sufficient; instead of being repeatedly reliant on the rest of the world to rescue them from tropical diseases they can successfully tackle themselves.

3. Also, tropical regions should find ways to develop and implement resources for the regions; and, they should stay away from "dreadlock corruptions mentalities" that have plagued tropical regions for centuries.

4. Tropical regions in critical community areas should and must undermine certain funerals' customs and traditions that have been proven to spread EBOLA from a diseased person to others living persons.

\section{Other Regions}

1. Other regions should know that the impacts of globalization (Global Village) makes tropically neglected diseases like polio, dengue fever, and particularly EBOLA closer to home, than ever.

2. Secondly, other regions should understand that whatever happens in the tropical regions can easily mushroom tropically; but, resurface in other regions symmetrically; instead of systematically and EBOLA is a critical example of such.

3. CDC should continue to develop and implement international public health policies that can eventually bring some positive social changes to the rest of the world prior to becoming epidemics; regardless of their locations.

4. Also, charity organizations should find better ways of financially sponsoring developments and implementations of assistances without allowing such resources to end up in the hands of corrupt tropical leaderships. As such, positive collaboration is a must in achieving success when dealing with contagious diseases particularly EBOLA.

5. Finally, other regions in particularly tropical regions in general should understand that EBOLA is an extremely contagious disease; and, vaccination is a must; regardless of one's historic traditions, culture, or religious beliefs.

\section{Pharmaceutical Companies}

1. Pharmaceutical companies should and must understand that EBOLA was initially discovered in 1976 and since then, no vaccine or medication efforts had been initiated.

2. Pharmaceutical companies should and must understand that instead of holistically operating on for-profit only singularly, periodic philanthropic approaches other companies have implemented worldwide, which are always effective, efficient, and proficient across the board and pharmaceutical companies should come to the charities' drawing board worldwide.

3. Pharmaceutical companies should and must also understand that since EBOLA's outbreaks in 2014 and 2015, endless philanthropists worldwide have donated hundreds of millions of dollars to assist humanistic Ebola's survival sustainability goals; and, the pharmaceutical companies should take advantage of the process at hand financially.

\section{Acknowledgements}

We want to use this opportunity to thank "University of Phoenix Houston Campus Colloquium Research Drive" which has motivated this study. We also want to thank the UOP's Campus College Chair, Colloquium academics leaders, administrators, committee, and team members for encouraging collaborative holistic participations in research studies; which should be fundamentally intriguing and eventually helpful to society as a whole.

\section{References}

[1] CDC (2015) National Institute for Occupational Safety Health (NIOSH). Center for Disease Control and Prevention (CDC). Workplace and Safety \& Health Topics. http://www.cdc.gov/niosh/topics/ebola/

[2] The Washington Post (2014) Convincing West Africans and Ebola... https://www.washingtonpost.com/news/the-intersect/wp/2014/09/22/4chans-latest-terrible-prank-convincing-west-afric ans-that-ebola-doctors-actually-worship-the-disease/

[3] The Washington Post (2015) Convincing West Africans and Ebola... https://www.washingtonpost.com/news/the-intersect/wp/2014/09/22/4chans-latest-terrible-prank-convincing-west-afric 
ans-that-ebola-doctors-actually-worship-the-disease/

[4] World Health Organization (WHO) (2013) Department of Communicable Disease Surveillance and Response. http://www.who.int/csr/resources/publications/surveillance/plague.pdf

[5] Byrne, J.P. (2008) Encyclopedia of Pestilence, Pandemics, and Plagues: A-M. ABC-CLIO, 413.

[6] Lozano, R., Naghavi, M., Foreman, K., Lim, S., Shibuya, K., Aboyans, V., Abraham, J., Adair, T., Aggarwal, R., Ahn, S.Y., et al. (2012) Global and Regional Mortality from 235 Causes of Death for 20 Age Groups in 1990 and 2010: A Systematic Analysis for the Global Burden of Disease Study 2010. The Lancet, 380, 2095-2128. http://dx.doi.org/10.1016/S0140-6736(12)61728-0

[7] McNeil Jr., D.G. (2015) Fewer Ebola Cases Go Unreported than Thought, Study Finds. New York Times. http://apps.who.int/ebolaweb/sitreps/20141231/20141231.pdf

[8] Bennett, M. and Palau, R.G. (2013) Polio in Afghanistan and Pakistan: Prospects for Eradication. https://www.cimicweb.org/cmo/afg/Documents/Social_Infrastructure/201311_CFC_Polio_Afghanistan_Pakistan.pd

[9] Anonymous (2006) Etymologia: Dengue. Emerging Infectious Diseases, 12, 893. http://dx.doi.org/10.3201/eid1206.ET1206

[10] Gubler, D.J. (1998) Dengue and Dengue Hemorrhagic Fever. Clinical Microbiology Reviews, 11, 480-496.

[11] WHO (2012) Global Strategy for Dengue Prevention and Control. World Health Organization, Geneva, 16-17.

[12] Neglected Tropical Diseases (2013) The 17 Neglected Tropical Diseases. World Health Organization, Geneva.

[13] WHO (2009) Dengue Guidelines for Diagnosis, Treatment, Prevention and Control. World Health Organization, Geneva.

[14] Torrey, E.F. and Yolken, R.H. (2005) Their Bugs Are Worse Than Their Bite. Washington Post, April 3, B01.

[15] World Health Organization (2014) Ebola Situation Report, 28 October 2015. http://apps.who.int/ebolaweb/sitreps/20141231/20141231.pdf

[16] Creswell, J.W. (2009) Research Design: Qualitative, Quantitative, and Mixed Methods Approach. 3rd Edition, Sage Publications, Inc., Thousand Oaks.

[17] Miller, R.G. (1981) Simultaneous Statistical Inference. 2nd Edition, Springer-Verlag, New York.

[18] Morrow, J. (2011) The T-Tests for Independent Variables/Introduction to Hypothesis. Laureate Education, Inc., Baltimore.

[19] Frankfort-Nachmias, C. and Nachmias, D. (2000) Research Methods in the Social Sciences. 6th Edition, Wadsworth, New York.

[20] Frankfort-Nachmias, C. and Nachmias, D. (2008) Research Methods in the Social Sciences. 7th Edition, Worth, New York.

[21] World Health Organization (2015) Ebola Situation Report, 28 October 2015. http://apps.who.int/ebolaweb/sitreps/20141231/20141231.pdf

[22] World Health Organization (2015) Ebola Transmission in Liberia over: Nation Enters 90-Day Intensive Surveillance Period. http://apps.who.int/ebolaweb/sitreps/20141231/20141231.pdf

[23] WHO (2014) Ebola Response Roadmap Situation Report.

[24] WHO (2015) Ebola Situation Report, 18 January 2015. World Health Organization, Geneva.

[25] WHO (2014) Ebola Response Roadmap-Situation Report 24 December 2014. World Health Organization, Geneva.

[26] WHO (2015) Ebola Situation Report. World Health Organization, Geneva. file:///C:/Users/owner/Desktop/Ebola.html

[27] WHO (2015) WHO/Europe-United Kingdom Is Declared Free of Ebola virus Disease.

[28] WHO (2014) Situation Summary Data Published on the 4th of December 2014. World Health Organization, Geneva.

[29] CDC (2015) Center for Disease Control and Prevention (CDC) 24/7: Saving Lives, Protecting People. http://www.cdc.gov/vhf/ebola/

[30] CDC (2014 \& 2015) Center for Disease Control and Prevention (CDC). Ebola Outbreak 2014. http://www.cdc.gov/media/dpk/2014/dpk-ebola-outbreak.html

[31] Atatah, P.E., et al. (2013) Analysis of Variance in Recidivism between Special Needs Offenders and Regular Offender Populations in Texas. Statistical Significant Differences Multiplier. (SSDM), Published Dissertation, Walden University, Minneapolis.

[32] Atatah, P.E. and Kisavi-Atatah, C.W. (2015) Globalization: Revisiting Neglected Tropical Diseases Such as Malaria and Measles. Open Journal of Social Sciences, 3, 45-56. http://dx.doi.org/10.4236/jss.2015.311007 
[33] Black, F.L. (1966) Measles Endemicity in Insular Populations; Critical Community Size and Its Evolutionary Implications. Journal of Theoretical Biology, 11, 207-211. http://dx.doi.org/10.1016/0022-5193(66)90161-5

[34] United Nations (UN) (2013) Millennium Development Goals Reports. United Nations, Manhattan.

[35] Offit, P.A. (2007) Vaccinated: One Man’s Quest to Defeat the World’s Deadliest Diseases. Smithsonian, Washington DC.

[36] BBC News (2006) Measles Hits Rare Andaman Tribe. BBC News, May 16, 2006 (Live Attenuated Measles Vaccine. EPI Newsletter/C Expanded Program on Immunization in the Americas, 2, 6. 1980).

[37] CDC (2015) Center for Disease Control and Prevention (CDC). Ebola and Travelers’ Health. http://wwwnc.cdc.gov/travel/diseases/ebola

[38] CDC (2014 \& 2015) Center for Disease Control and Prevention (CDC). Ebola Outbreak 2014. http://www.cdc.gov/media/dpk/2014/dpk-ebola-outbreak.html

[39] CDC (2014 \& 2015) Center for Disease Control and Prevention (CDC). Quarantine: Sea and Air Travel. http://www.cdc.gov/quarantine/air/managing-sick-travelers/ebola-guidance-airlines.html

[40] CDC (2014 \& 2015) Center for Disease Control and Prevention (CDC). The Quarantine Situation. http://www.cdc.gov/quarantine/air/managing-sick-travelers/ebola-guidance-airlines.html

[41] CDC (2014 \& 2015) Center for Disease Control and Prevention (CDC). About Quarantine and Isolation. http://www.cdc.gov/quarantine/quarantineisolation.html

[42] CDC (2014 \& 2015) Center for Disease Control and Prevention (CDC). Legal Authority for Isolation and Quarantine. http://www.cdc.gov/quarantine/aboutlawsregulationsquarantineisolation.html

[43] CDC (2014 \& 2015) Center for Disease Control and Prevention (CDC). Airplane Guidelines. http://www.cdc.gov/quarantine/air/index.html

[44] Berger, P.L. and Luckmann, T. (1966) The Social Construction of Reality: A Treatise in the Sociology of Knowledge. Doubleday \& Company, New York.

[45] Atatah, P.E. and Kisavi-Atatah, C.W. (2015) The Paradigm of Life. Unpublished. 